\title{
Relationship between the loss of maxillary anterior alveolar bone and the duration of untreated lepromatous leprosy in Malaysia
}

\author{
SEANG HOO NAH,* S C MARKS $\dagger \ddagger \&$ KRISHNAN \\ SUBR AMANIAM* \\ *Department of Anatomy, Faculty of Medicine, University of \\ Malaya, Kuala Lumpur, Malaysia; †Department of Anatomy, \\ University of Massachusetts Medical School, 55 Lake Avenue, \\ Worcester, Massachusetts 01605, USA
}

Accepted for publication 7 September 1984

\begin{abstract}
Summary Alveolar bone loss and the duration of untreated disease were compared in 31 patients with lepromatous leprosy. In general, those patients with the longest confirmed untreated disease also had the greatest alveolar bone loss in the anterior maxilla. These data, taken together with previous observations, suggest that early detection and uninterrupted treatment of lepromatous patients will reduce the osseous deformities of the disease.
\end{abstract}

\section{Introduction}

Skeletal involvement is a serious complication of leprosy manifested as a net loss of skeletal mass, ${ }^{1-5}$ probably due to an acceleration of bone resorption mediated by osteoclasts and osteolytic osteocytes. ${ }^{6}$

Resorption of alveolar bone was first noted by Moller-Christensen ${ }^{2,7,8}$ in maxillae from skeletal remains of Danes with leprosy in medieval Denmark. These observations have been confirmed and extended in contemporary populations of patients with leprosy by several investigators. ${ }^{9-15}$ These studies have shown that resorption of the alveolar process in the maxilla is a characteristic manifestation of leprosy.

Previously we have examined alveolar bone loss in leprosy and shown that it is greater in the anterior maxilla than other areas of the jaws, that the amount of bone resorption is greater in patients with lepromatous disease, and that the rate of bone loss in treated patients is surprisingly low. ${ }^{13,15}$ These data suggest that the

$\ddagger$ Reprints: S C Marks, Department of Anatomy, University of Massachusetts Medical School, 55 Lake Avenue, Worcester, Massachusetts 01605, USA. 
greater reduction in alveolar bone height in patients with lepromatous disease is the result of bone lost before treatment is initiated. This investigation compared the magnitude of such bone loss and the duration of untreated disease in 31 patients with lepromatous leprosy.

\section{Material and methods}

Thirty-one patients with lepromatous leprosy were selected from the patient population at the National Leprosy Control Centre, Sungei Buloh, Malaysia. Lepromatous disease was determined by smears and clinical examination. ${ }^{16}$ All patients were under treatment with dapsone, and none were among the $10 \%$ of lepromatous patients in Malaysia whose relapses were due to dapsone resistance (MFR Waters, personal communication). All procedures were explained in detail to each patient who gave written informed consent in advance.

Each patient was questioned exhaustively by us and colleagues at Sungei Buloh and the University of Malaya as to the time and form of the first appearance of signs and symptoms of leprosy, the time and form of first treatment and the regularity of treatment. We noted the time of appearance of the earliest signs of disease [nasal stuffiness, crust formation and discharge and oedema of the legs and ankles at the end of the day ${ }^{16}$ ], as well as indications of more advanced disease such as anaesthesia, paralysis and cutaneous ulcers. Some of these data were available from the patient's chart and served as a measure of the reliability of each patient's memory. Dapsone therapy was first used at Sungei Buloh in 1947, and by 1949 all patients were being treated with this drug. Using this information and that derived from a detailed medical history, we were able to establish for most patients a reasonable record of the length of recognized but untreated disease and the type and continuity of treatment to the present.

Alveolar bone loss in the anterior maxilla, was measured radiographically ${ }^{17}$ as described previously ${ }^{13}$ using periapical radiographs taken with the paralleling long-cone technique. ${ }^{18}$ This method permits the reduction in alveolar bone height interproximally to be expressed as a percentage by subtracting the current bone level, related to the root length of the maxillary incisor, from that present initially, presumed to be the full length of the root to the level of the cemento-enamel junction. $^{15}$

These data from the detailed medical and treatment histories and measurements of alveolar bone height were used to examine the potential correlation of alveolar bone loss and the duration of untreated lepromatous disease.

\section{Results}

Our observations on each patient are presented in Figure 1, where the mean maxillary anterior alveolar bone resorption is plotted against the duration of 

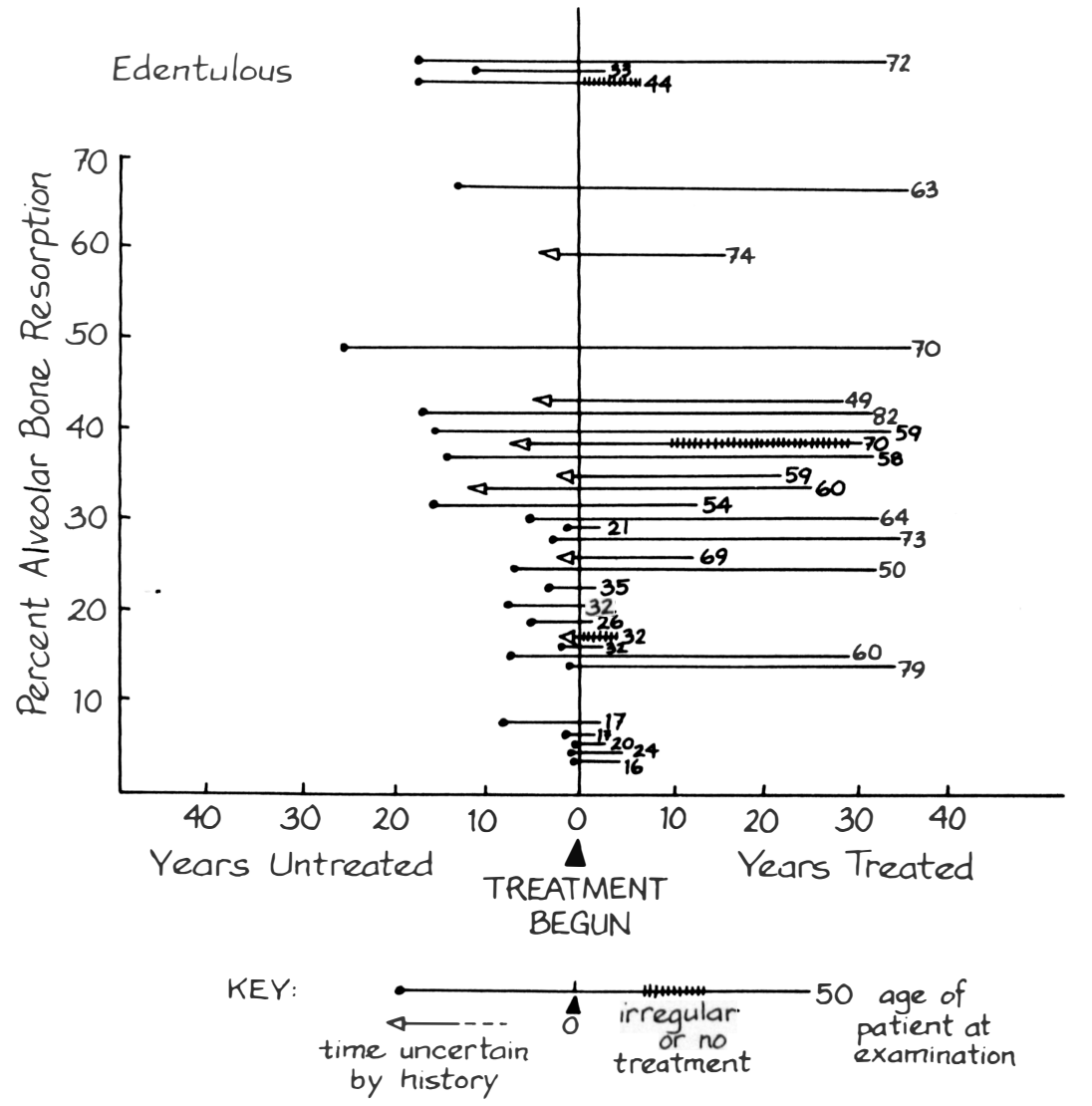

Figure 1. Graphic illustration of the relationship between magnitude of alveolar bone loss, first signs of the disease and treatment record of patients with lepromatous leprosy. Each patient is represented by a single horizontal line, whose vertical position corresponds to the reduction in height of alveolar bone in the anterior maxilla. The total length of the line represents the known duration of the disease. An arrowhead at the left of the line indicates that the time of initial signs and symptoms of disease is uncertain by patient history or record. Interruption of treatment is indicated by short vertical bars.

untreated and treated disease. Uncertainty about the time treatment began, as well as regularity of treatment, are indicated by individual symbols. Notice that there is a tendency for greater bone loss to be associated with a longer period of untreated disease. This is best illustrated by the 5 individuals aged 79, 60, 73, 70 and 70 whose bone loss was $14,15,28,38$ and $48 \%$ and length of untreated disease was 2, 8, 4, greater than 8 and 26 years, respectively. However, this association is not without exception.

These data are summarized in Table 1. In general, patient age and duration of untreated disease increase with bone loss in categories with more than 1 individual. Edentulous patients were untreated for longer than 10 years. 
Table 1. Summary of observations

\begin{tabular}{lccc}
\hline $\begin{array}{c}\text { Alveolar bone } \\
\text { resorption (\%) }\end{array}$ & $\begin{array}{c}\text { Number } \\
\text { of patients }\end{array}$ & $\begin{array}{c}\text { Mean age } \\
\text { of patients }\end{array}$ & $\begin{array}{c}\text { Mean duration } \\
\text { untreated disease (years) }\end{array}$ \\
\hline $0-10$ & 5 & 19 & 3 \\
$11-20$ & 5 & 46 & $4 \cdot 5$ \\
$21-30$ & 7 & 49 & $5 \cdot 3$ \\
$31-40$ & 6 & 60 & 17 \\
$41-50$ & 3 & 67 & 21 \\
$51-60$ & 1 & 74 & $>4$ \\
$61-70$ & 1 & 63 & 13 \\
Edentulous & 3 & 50 & 16 \\
\hline
\end{tabular}

\section{Discussion}

Previous work has shown that resorption of alveolar bone in the anterior maxilla is a characteristic skeletal deformity of leprosy, ${ }^{2,8,9}$ that is probably caused by a local activation of osteoclasts. ${ }^{14}$ This bone loss is most pronounced in patients with lepromatous disease ${ }^{13}$ and in patients in Malaysia is as advanced in the fourth decade as is bone loss in the sixth decade in patients without leprosy in the general population. ${ }^{13}$

Nevertheless, alveolar bone loss in patients under continuous treatment is very low in spite of general poor oral hygiene. ${ }^{15}$ The present report suggests that the amount of alveolar bone loss in patients with lepromatous leprosy is related to the duration of untreated disease.

These data taken together suggest that early detection and treatment of leprosy are effective ways to minimize bone loss and skeletal deformities and that immune dysfunctions in patients with leprosy may protect them from the alveolar bone loss that accompanies the periodontal diseases. ${ }^{15}$

The cause of the local activation of osteoclasts in alveolar bone of these patients, be it the leprosy bacillus itself or its metabolic products, deserves further study.

\section{Acknowledgments}

This work was supported in part by a grant from the Heiser Program for research in leprosy and grant no 135/77 from the University of Malaya.

We thank the director and staff of the National Leprosy Control Centre, Sungei Buloh, Selangor, Malaysia for their enthusiastic support. We are particularly indebted to Mr Chiew Hock Koon for his superb skills as an assistant 
and to the patients who willingly participated in this study. We thank Dr V Moller-Christensen for reviewing the manuscript and M Manzello for secretarial assistance.

S C Marks was Visiting Professor of Anatomy and supported by a Visiting Investigator Award from the Heiser Program for Research in Leprosy.

\section{References}

1 Lechat MF. Bone lesions in leprosy. Int J Lepr, 1962; 30: 125.

2 Moller-Christensen V. Ten lepers from Naestved in Denmark. A study of skeletons from a medieval leper hos pital. Copenhagen, Danish Science Press, Ltd. 1953, p. 160.

3 Negre A, Fontan R. Contribution a l'étude de la pathogenie des lesions osseuses de la lèpre. Int $J$ Lepr, 1956; 24: 164.

4 Paterson DE. Bone changes in leprosy: their incidence, progress, prevention and arrest. Int $J$ Lepr, 1961; 29: 393.

5 Warren G. Tarsal bone disintegration in leprosy. J Bone Jnt Surg, 1971; 53B: 688.

6 Marks SC Jr. The cellular basis for extremity bone loss in leprosy. Int J Le pr, 1979; 47: 26.

7 Moller-Christensen V, Bakke SN, Melsom RS, Waaler E. Changes in the anterior nasal spine and alveolar process of maxillary bone in leprosy. Int J Lepr 1952; 20: 335.

8 Moller-Christensen. V. Le prosy changes of the skull. Odense, Denmark, Odense University Press, 1978.

9 Michman J, Sagher F. Changes in the anterior nasal spine and the alveolar process of the maxillary bone in leprosy. Int J Lepr 1957; 25: 217.

10 Moller-Christensen V. Changes in the anterior nasal spine and the alveolar process of the maxilla in leprosy. A clinical examination. Int J Lepr 1974; 42: 431.

11 Rendall JR, McDougall AC. Reddening of the upper central incisors associated with periapical granuloma in lepromatous leprosy. Br J Oral Surg, 1976; 13: 271.

12 Southam JC, Venkataraman BK. Oral manifestations of leprosy. Br J Oral Surg, 1973; 10: 272.

13 Subramaniam K, Marks SC. Alveolar bone loss in leprosy. A clinical and radiological study. Lepr Rev, 1978; 49: 287.

14 Marks SC, Jr, Subramaniam K. The cellular basis for alveolar bone loss in leprosy. Lepr Rev, 1978; 49: 297.

15 Subramaniam K, Marks SC, Nah SH. The rate of loss of maxillary anterior alveolar bone height in patients with leprosy. Lepr Rev, 1983; 54: 119.

16 Jopling WH. Handbook of Leprosy, 2nd ed. London, Heinemann Medical Books Ltd, 1978.

17 Schei O, Waerhaug J, Lovdal A, Arno A. Alveolar bone loss as related to oral hygiene and age. $J$ Clin Period, 1959; 30: 7.

18 Lang NP, Hill RW. Radiographs in periodontics. J Clin Period, 1977; 4: 16. 